\title{
Preferencias divergentes de los lectores y de los periodistas en las noticias on-line
}

\author{
Pablo BozcKowski* \\ pjb9@northwestern.edu
}

(Abstracts y palabras clave al final del artículo)

Propuesto: 15 de enero de 2013

Evaluado: 17 de enero de 2013

Aceptado: 18 de enero de 2013

El cuerpo político, como el cuerpo biológico, precisa de una correcta combinación de nutrientes para funcionar adecuadamente. Uno de esos ingredientes clave son las noticias sobre asuntos públicos, necesarias para dar forma a la deliberación política y para animar a la ciudadanía, a la participación bien informada. En la mayoría de las sociedades liberales democráticas las noticias las proporcionan en gran medida las organizaciones informativas de referencia en forma impresa, en la radio y televisión, y en el medio digital. Pero en el medio digital, aunque dichas organizaciones proporcionan grandes cantidades de noticias de esta naturaleza, la demanda de noticias por parte de los lectores está virando hacia otro tipo de contenidos también suplidos por estos medios, como información del tiempo, deportes, crimen, cotilleo y entretenimiento. Ello plantea un interesante dilema para estos medios, y también para la sociedad en general.

\section{MEDICIÓN DE LA DIVERGENCIA EN LAS NOTICIAS DIGITALES}

En principio yo no investigaba la divergencia en las noticias on line. Pero una vez que aparece tal divergencia en este contexto, comencé a interesarme por su frecuencia y encontré que en todas partes se reproducía dicho fenómeno.

\footnotetext{
* Pablo J. Boczkowski es profesor en Departmento de Communication Studies, y Director del Programa en Media, Tecnología y Sociedad en la Northwestern University. Especialista en Etnografía del periodismo profesional, sus textos Digitizing the News: Innovation in Online Newspapers (MIT Press, 2004 trad. española en Gedisa) y el reciente, News at Work: Imitation in an Age of Information Abundance (University of Chicago Press, 2010) le han valido el reconocimiento como investigador internacional de la dinámica creada por el surgimiento del medio digital, la crisis en el periodismo impreso y la influencia de las tecnologías en el medio informativo. ".Publicado originalmente en la Revista ACM | November 2010 | vol. 53 | no. 11, pp 24-26.Agradecemos al autor y a la revista su permiso de publicación.
} 
Preparando un libro sobre imitación de informaciones en las noticias digitales y en prensa ${ }^{1}$, tuve que registrar las preferencias de los lectores y la composición temática de las mismas. Lo que encontré fue una profunda divergencia, de dos dígitos de extensión, entre las noticias ofrecidas por los periodistas, y las noticias demandadas por los lectores de Internet.

Más precisamente, calculé el grado de similitud en los asuntos noticiosos considerados más importantes en todos los ciclos informativos, cubiertos por las tres principales cabeceras digitales de la prensa argentina. Ello implicaba recopilar las diez noticias de primera página, de izquierda a derecha, y de arriba abajo, en un sistema de medición de rejilla, por decir así. El análisis buscaba determinar si un suceso cubierto en un sitio web era también tratado por algún otro.

El alto nivel de similitud entre los sitios webs analizados no podía explicarse por la naturaleza de la demanda. En cualquier caso, los consumidores parecían exigir productos informativos más diferenciados y noticias marcadas por una diferente composición temática a la que se les ofrecía. Las webs coincidían en un $52 \%$ de las noticias que ofrecían entre sus 10 relatos de mayor importancia. Casi el 59\% de estos relatos versaban sobre temas políticos, económicos, financieros, e internacionales.

Sin embargo, las noticias más populares entre los lectores de esas webs eran muy diferentes: sólo el 36\% de las noticias duras consideradas más impactantes por los medios estaban entre las 10 noticias más vistas en al menos uno de esos medios, y solamente el $32 \%$ de las noticias más vistas en más de uno de dichos medios digitales versaba sobre política, economía, negocios o temas internacionales. Estos datos arrojaron un hito o divergencia de 16 puntos porcentuales en la selección de las 10 noticias más importantes, entre la elección realizada por los periodistas y la de los lectores, y una distancia de 27 puntos en la composición temática de dicha selección.

Este hallazgo inicial me llevó a plantear la siguiente cuestión: ¿se da el mismo patrón en otras partes del mundo?. Un segundo estudio arrojó el mismo resultado divergente para la prensa de referencia radicada en los Estados Unidos. Mi colaborador Limor Peer de la Universidad de Yale y yo analizamos la selección de noticias común entre periodistas y lectores, en 4 medios periodísticos digitales de primera importancia en USA: CNN, Yahoo News, Chicago Tribune, y el ya desaparecido Seattle Post-Intelligencer ${ }^{2}$. Escogimos estos medios para que representaran a las empresas con filiales televisivas, digitales y de prensa en papel, y además con distintas orientaciones geográficas. Los dos primeros eran medios nacionales y globales, en tanto que los dos últimos eran locales.

En todos los casos, los periodistas seleccionaban más noticias políticas, económicas, finacieras o internacionales que los lectores, quienes a su vez se interesaban más por las noticias del tiempo, deportes, entretenimiento y sucesos. Para cada día seleccionado de la muestra, los investigadores recopilaron las 10 noticias más importantes, según el criterio de los periodistas y según los lectores respectivamen-

\footnotetext{
1. Boczkowski, P. News at Work: Imitation in an Age of Information Abundance. University of Chicago Press, Chicago, IL, 2010.

2 Boczkowski, P. and Peer, L. (in press)". The choice gap:The divergent online news preferences of journalistsand consumers". Journal of Communication.
} 
te, tal y como se había hecho en el estudio anterior. La comparación entre la selección de los periodistas y la de los lectores reveló una diferencia porcentual del 13\% en el caso del Seattle Post-Intelligencer y en Yahoo, un porcentaje del 14\% en CNN, y un porcentaje del 17 de divergencia en el Chicago Tribune.

Tuvimos en cuenta que la demanda y la oferta de noticias son interdependientes: los periodistas seleccionan determinadas noticias porque creen que serán atractivas para los lectores, y los lectores leen informaciones porque ven que reciben un tratamiento más extenso por los periodistas. Para solventar ese factor, realizamos un segundo estudio en el que eliminamos las noticias seleccionadas igualmente por periodistas y lectores. Al centrarnos en las informaciones publicadas por los periodistas independientemente de su popularidad entre los lectores, y en las noticias elegidas por los lectores a pesar de su lugar secundario de tratamiento por los informadores, obtendríamos una medición más certera de las preferencias de ambos grupos.

Los resultados indican que independientemente de la influencia recíproca entre periodistas y lectores, hay una trayectoria claramente divergente en las preferencias de lectores y periodistas. La distancia entre las preferencias informativas temáticas de periodistas y lectores llega hasta un $19 \%$ de puntos porcentuales.

¿Depende dicha divergencia entre oferta y demanda, de la geografía o de la ideología? Los resultados de un tercer estudio, realizado en colaboración con los estudiantes de grado Eugenia Mitchelsten y Martin Walter de la Universidad de Northwestern, indican que la divergencia es un fenómeno extendido a todo tipo de medios de diferentes países y regiones, con muy diversa historia, contexto cultural o posición ideológica. ${ }^{3}$

Este estudio extendió la muestra analizada a 11 medios de Europa Occidental y de Latinoamérica: The Guardian y The Times en Inglaterra; El Pais y El Mundo en España; Die Welt y Tagesspiegel en Alemania; Reforma y El Universal in Mexico; Clarin y La Nacion en Argentina; y Folha de Sao Paulo en Brasil (sólo analizamos un periódico en Brasil porque los datos del segundo medio digital en este país no eran públicos). Todos estos medios eran medios generalistas, de referencia y consumo mayoritarios, de alcance nacional en sus respectivos países. Además, en los cinco países en los que elegimos dos medios, éstos representaban dos opciones aproximadamente divergentes, siendo uno conservador y otro progresista o más liberal.

De nuevo nos encontramos un hito temático de divergencia en la selección entre oferta y demanda, con los periodistas más proclives a noticias políticas, económicas, financieras e internacionales, con referencia a las de los lectores. La diferencia de elección entre periodistas y lectores llegó a un 30\% en el caso de The Guardian y bajó a un $9 \%$ en el caso del diario Clarín, siendo la media de un 19\%. Por otra parte no encontramos una variación significativa en los medios de acuerdo con situaciones geográficas, o ideológicas. La divergencia de criterio entre periodistas y lectores alcanzaba un $20 \%$ en los medios europeos occidentales y un $19 \%$ en los medios

\footnotetext{
3 Boczkowski, P., Mitchelstein, E., and Walter, M. (en prensa). "Convergence across divergence: Understandingthe gap in the online news choices of journalists and consumers in Western Europe and Latin America". Communication Research.
} 
hispanoamericanos. En los medios conservadores la distancia llega al 21\%, mientras que en los diarios más progresistas es de un $19 \%$.

\section{EL FUTURO DE LOS MEDIOS Y LA DEMOCRACIA}

No parece que la distancia establecida en la demanda y la oferta de los lectores de medios y los periodistas, sea algo que haya nacido con la Red. Como Robert E. Park, académico y periodista, afirmara muchas décadas atrás, "las cosas que la mayoría de nosotros deseamos ver impresas no son las mismas cosas que queremos leer. Ansiamos ver publicadas cosas que sean o que parezcan ser edificantes, pero leemos las cosas que son interesantes". Pero la sólida posición de estos medios de élite en el mercado implica que los anunciantes, interesados en los lectores como consumidores potenciales, pueden ser satisfechos y a la vez los periodistas conseguir cumplir con el sentido del deber cívico, difundiendo noticias "edificantes" de muy limitado atractivo para el público en general.

Sin embargo la situación en los media contemporáneos, de alta competición, hace que muy pocos medios disfruten del natural monopolio u oligopolio que los periódicos y las televisiones tuvieron en el pasado. Quizás ya nadie lo tiene. De todos los medios actuales, la Red es el que más competitivo resulta por la ausencia de barreras geográficas y de distribución, y el elevado número de actores que implica.

La web implica además la posibilidad de seguir en detalle automáticamente el número de lecturas que un relato noticioso tiene. Esto significa que los medios de referencia tienen perfecta evidencia del hueco existente entre los intereses de la demanda y los de la oferta periodística. Ellos deben afrontar el dilema que hemos planteado al comienzo de este artículo, diariamente.

¿Qué deben hacer? Si siguen en su línea y la demanda de los consumidores no cambia (lo que parece ser el caso), el desencuentro entre las preferencias de periodistas y lectores implica una erosión de la sostenibilidad económica de los medios. Si por el contrario cambian de táctica y hacen más caso a lo que los lectores demandan, pagarán el precio convirtiéndose en organizaciones mediáticas totalmente diferentes a lo que son ahora, debiendo competir en una ya congestionada arena de "medios populistas". En cualquiera de los casos, el futuro no se presenta para ellos muy prometedor.

Las implicaciones que estas tendencias potenciales plantean a la democracia tampoco son muy alentadoras. Como hemos dicho, los medios informativos de élite y referencia son grandes contribuyentes de ideas políticas, económicas e internacionales esenciales para la participación y la toma de decisiones en una democracia bien informada. Esta información es más difícil encontrarla en otro tipo de plataformas, como los tabloides o los blogs ( que amplifican en gran medida la información que se encuentra en los medios informativos de referencia).

El apetito social de información puede saciarse con información del tiempo, deportes, sucesos o cotilleos. Pero la aportación de nutrientes de estas fuentes para el cuerpo político y social en funcionamiento, puede ser muy carencial. Si en gran medida somos lo que comemos, podemos decir que somos las noticias que consu- 
mimos. Y cuando el suministro y el consumo de noticias difieren, no solamente enfermarán los medios informativos, sino también nosotros mismos.

\title{
RESUMEN
}

Este artículo analiza un fenómeno nuevo en el periodismo de las sociedades desarrolladas, como es la divergencia entre los intereses y demanda de contenidos de los lectores y los criterios de los periodistas profesionales a la hora de seleccionar las noticias. Explica el autor su método de investigación para apoyar esta hipótesis, y los cambios y evolución que están poniendo en jaque al periodismo en Europa y los Estados Unidos.

Palabras clave : preferencias de los lectores, periodismo, noticias, medios informativos, crisis.

\begin{abstract}
:
This paper analyses a new phenomenon of divergence between readers' interests and contents demand and professional journalists' criteria of selection of the news in the developed societies. It explains a research method to conclude this hypothesis, and refers to the changes and evolution that now are challenging journalism in Europe and USA.
\end{abstract}

Key words: reading preferences, journalism, news, interests, news media, crisis

\section{RÉSUMÉ}

Cet article analyse un phénomène nouveau dans le journalisme des sociétés développées, que présentent une divergence des intérêts et demande de contenus des lecteurs respect à la sélection des nouvelles des journalistes processionnaux. L'auteur expose sa méthode de recherche et les changements et l'évolution que sont en train de défier le journalisme en Europe comme aux États Unis.

Mots clé: preferences des lecteurs, journalisme, nouvelles, medias informatifs, crise. 